\title{
Analisa Biaya Penggunaan Seftriakson dan Siprofloksasin Pasien Infeksi Saluran Kemih di Rumah Sakit X Kabupaten Jombang Tahun 2017
}

\author{
Cost Analysis of Ceftriaxone and Ciprofloxacin on Urinary Tract \\ Infection Patients at X Hospital in Jombang 2017 \\ Anggi Restyana ${ }^{1 *}$, Wika Admaja ${ }^{2}$ \\ ${ }^{1}$ Program Studi Farmasi, Fakultas IImu Kesehatan, Universitas Kadiri, Kediri \\ JI Selomangleng No. 1 Pojok Mojoroto Kota Kediri, Indonesia \\ ${ }^{2}$ Program Studi S1 Farmasi, Institut IImu Kesehatan Bhakti Wiyata Kediri, \\ J. Wachid Hasyim No 56 Kota Kediri, Indonesia \\ *Corresponding author email: anggi.restyana@unik-kediri.ac.id
}

Received 7-11-2019 Accepted 25-11-2019 Available online 30-12-2019

\begin{abstract}
ABSTRAK
Jumlah penderita Infeksi Saluran Kemih (ISK) mencapai 90-100 kasus per 100.000 penduduk per tahun. Dalam penanganannya berbagai macam antibiotik digunakan sebagai terapi pengobatan termasuk siprofloksasin. Saat ini siprofloksasin merupakan antibiotik pilihan pertama dalam terapi ISK di Rumah Sakit X Kabupaten Jombang. Penelitian ini bertujuan untuk membandingkan biaya terapi penggunaan antibiotik seftriakson dan siprofloksasin pada pasien infeksi saluran kemih. Telah dilakukan penelitian cost effectiveness analysis menggunakan metode observasi analitik dengan rancangan secara cross-sectional, pengambilan data secara retrospektif dengan menelusur dokumen rekam medis pasien. Metode analisis menggunakan statistic uji-t tidak berpasangan. Penelitian dilakukan pada perspektif rumah sakit. Populasi dalam penelitian ini sebanyak 164 pasien. Terdapat 64 pasien yang memenuhi kriteria inklusi. Sebanyak 32 pasien mendapatkan siprofloksasin dan 32 pasien mendapatkan seftriakson. Total biaya langsung rata-rata pasien ISK yang mendapatkan seftriakson adalah Rp902.908,3 sedangkan pasien yang mendapatkan siprofloksasin adalah Rp959.918,91. Efektivitas diukur berdasarkan probabilitas lama rawat yang ditentukan. Pasien dengan seftriakson memiliki lama rawat 4,468 hari dengan probabilitas 0,875 dan siprofloksasin memiliki lama rawat 4,688 hari dengan probabilitas 0,781. Berdasarkan efektivitas, nilai ACER seftriakson sebesar Rp1.031.895,28 dan nilai ACER siprofloksasin sebesar Rp1.229.089,51. Namun secara uji statistik tidak ditemukan perbedaan yang bermakna pada efektivitas dan biaya antara seftriakson dan siprofloksasin. Pada perhitungan nilai ICER pada penelitian ini didapatkan nilai sebesar Rp259.138,82. Artinya ada biaya tambahan sebesar Rp259.138,82 per outcome terapi.
\end{abstract}

Kata kunci: efektivitas biaya, infeksi saluran kemih, seftriakson, siprofloksasin. 


\begin{abstract}
The number of Urinary Tract Infection (UTI) patients reaches 90-100 cases in 100.000 population each year. Various types of antibiotics are used as therapeutic treatments of UTI, including ciprofloxacin. At present, ciprofloxacin is the first choice antibiotic for UTI therapy at $X$ hospital in Jombang. This study aims to compare the cost of ceftriaxone and ciprofloxacin therapy for the patient with UTI. This cost-effectiveness analysis study was carried out using an analytical observation method with a cross-sectional design, data were retrospectively collected by searching in the patient's medical record document. This research was conducted based on the perspective of hospital. Data were analyzed using an independent t-test. The population in this study was 164 patients, and 64 of them met the inclusion criteria. A total of 32 patients were given ciprofloxacin therapy and the other 32 patients were treated with ceftriaxone. The total direct cost of UTI patients treated with ceftriaxone was Rp902,908.37, while patients given ciprofloxacin was Rp959,918.91. The effectiveness was measured based on the probability of hospital length of stay. The length of stay and probability of patients treated with ceftriaxone were 4.468 days and 0.875 , respectively, while those of ciprofloxacin were 4.688 days and 0.781. Based on effectiveness, ACER of ceftriaxone and ciprofloxacin were $R p 1,031,895.28$ and $R p 1,229,089.51$, respectively. However, no significant difference was found on the effectiveness and cost between ceftriaxone and ciprofloxacin. ICER value on this study was Rp259,138.82; which indicated there was an additional cost of Rp259.138,82 per outcome therapy.
\end{abstract}

Key words: cost-effective, ceftriaxone, ciprofloxacin, urinary tract infection.

\section{Pendahuluan}

Angka kematian akibat Infeksi Saluran Kemih (ISK) mencapai angka lebih dari 13.000 (2,3\%) kasus tiap tahunnya. Angka insiden ISK di Jawa Timur sebanyak 24 kasus (Pranoto et al., 2012). Apabila ISK tidak dilakukan penanganan yang baik maka akan berkembang menjadi masalah yang serius.

Di AS, kurang lebih 15\% antibiotik diresepkan untuk masyarakat yang menderita ISK. Hal ini bersinergi dengan data di Eropa. Terhitung mencapai lebih dari 100.000 kunjungan rumah sakit setiap tahunnya. Studi pendahuluan yang diselenggarakan oleh Global Prevalence Infection Urology
(GPIU) menunjukkan $10-12 \%$ pasien yang masuk rumah sakit dalam unit urologi mengalami healthcare associated infection.

Data IAUI tahun 2015 menyebutkan terdapat tiga mikroorganisme terbanyak dalam kasus ISK yaitu Eschericia coli (17\%), Staphylococcus coagulase negative (11\%), dan Actinobacter baumannii (10\%) (Abbo dan Hooton, 2014; Perrault et al., 2017).

Di rumah sakit, fluorokuinolon dan sefalosporin biasanya diresepkan untuk memberikan cakupan empiris terhadap patogen E.coli di antara pasien ISK. Antibiotik golongan florokuinolon sebagai pilihan pertama diresepkan 
untuk terapi ISK terhadap bakteri Eschericia coli (Pranoto et al., 2012).

Penelitian

terdahulu

menyatakan bahwa seftriakson selain memiliki efektivitas pada terapi ISK komplikasi, obat ini juga memiliki cost yang lebih rendah dibandingkan dengan ertapenem dan levofloksasin. Pada penelitian menyebutkan bahwa jumlah sampel yang sensitif terhadap siprofloksasin $65,4 \%$ sedangkan pada seftriakson menunjukkan angka yang lebih besar yaitu sebanyak $76,9 \%$ dari total keseluruhan pasien (Firdiana dan Farida, 2016).

Pada saat ini Indonesia memiliki data terkait biaya pelayanan kesehatan yang dirasakan semakin meningkat. Hal ini disebabkan karena berbagai macam faktor, yaitu meliputi adanya perubahan pola penyakit dan pola pengobatan, peningkatan penggunaan teknologi canggih dalam penanganan kasus penyakit, meningkatnya permintaan masyarakat dan adanya perubahan ekonomi secara global. Di sisi lain biaya yang disediakan oleh pemerintah untuk pelayanan kesehatan belum dapat ditingkatkan, dimana kemampuan pemerintah semakin terbatas dan peran masyarakat masih belum maksimal (Admaja et al., 2019).

Cara yang berkesinambungan dalam menentukan hubungan ekonomi dari alternatif terapi obat atau alat kesehatan lain adalah dengan uji Analisis Efektivitas Biaya (AEB). Pada AEB, hasil pengobatan tidak diukur dalam unit moneter, melainkan didefinisikan dan diukur dalam unit alamiah, baik yang secara langsung menunjukkan efek suatu terapi atau obat maupun hasil selanjutnya dari efek terapi tersebut. AEB cukup sederhana dan banyak digunakan untuk kajian farmakoekonomi untuk membandingkan dua atau lebih intervensi kesehatan yang memberikan besaran efek berbeda. Dengan analisis yang mengukur biaya sekaligus hasilnya ini, pengguna dapat menetapkan bentuk intervensi kesehatan yang paling efisien membutuhkan biaya termurah untuk hasil pengobatan yang menjadi tujuan intervensi tersebut (Kemenkes, 2013).

Dalam hal ini diperlukan suatu evaluasi obat baru dalam terapi ISK. Berdasarkan hasil survei di Rumah Sakit $X$ Kabupaten Jombang terdapat beberapa antibiotik yang digunakan dalam terapi ISK yaitu, siprofloksasin, trimetoprim, dan seftriakson. Jumlah pasien yang terdiagnosa ISK sepanjang bulan Januari hingga Desember 2017 mencapai 164 pasien.

Penelitan AEB dilakukan dengan membandingkan biaya yang diperlukan pasien dengan outcome yang diperoleh di antara dua pilihan obat. Sampai saat ini, belum ada jurnal terpublikasi yang memberikan bukti efektivitas biaya antara antibiotik seftriakson dan siprofloksasin yang direkomendasikan untuk ISK di Indonesia. Sehingga peneliti tertarik untuk melakukan analisis efektivitas biaya penggunaan seftriakson dan siprofloksasin pada pasien ISK.

\section{Metode Penelitian}

Rancangan penelitian pada penelitian analisis efektivitas biaya terapi 
penggunaan antibiotik seftriakson dan siprofloksasin menurut perspektif rumah sakit pada pasien infeksi saluran kemih tahun 2017 adalah observasi analitik dengan menggunakan studi cross sectional retrospektif. Variabel independen adalah terapi antibiotik dan variabel dependen adalah biaya terapi.

Berdasarkan data rekam medis Rumah Sakit X Kabupaten Jombang tahun 2017 diketahui jumlah pasien yang memenuhi kriteria inklusi sebanyak 64 pasien, dimana 32 pasien mendapatkan terapi seftriakson dan 32 pasien mendapatkan terapi siprofloksasin sebagai terapi infeksi saluran kemih.

Bahan yang digunakan untuk penelitian ini adalah data dari dokumen rekam medik pasien dan data biaya riil selama rawat inap di rumah sakit. Sampel yang digunakan dalam penelitian ini adalah pasien terdiagnosa ISK di Rumah Sakit X Kabupaten Jombang pada tahun 2017. Teknik pengambilan sampel dilakukan secara purposive sampling.

Adapun beberapa kriteria inklusi dan eksklusi sampel adalah sebagai berikut: kriteria inklusi mencakup pasien rawat inap, pasien berumur $\geq 26$ tahun tanpa penyakit penyerta, lama rawat minimal 1 hari, pasien yang mendapatkan antibiotik seftriakson, dan pasien yang mendapatkan antibiotik siprofloksasin. Kriteria eksklusi meliputi: pasien memiliki data rekam medis yang tidak lengkap, pasien yang masuk rumah sakit dengan diagnosis sepsis.

\section{Tahap Pengumpulan Data}

Tahap persiapan dilakukan melalui survei populasi di Rumah Sakit X
Kabupaten Jombang. Pengambilan data dari rekam medis terhadap pasien dilakukan dari tanggal 1 Januari 2017 sampai 31 Desember 2017, kemudian dilakukan pencatatan pada lembar pengamatan meliputi data diri pasien dan lama rawat.

Pengambilan data keuangan yakni biaya terapi dilihat dari catatan pembayaran pasien di bagian keuangan. Sedangkan data biaya obat diambil dari instalasi farmasi. Kemudian seluruh data biaya diakumulasi untuk mengetahui biaya keseluruhan selama pasien dirawat.

Analisis yang dilakukan adalah analisis karakteristik kemudian pengukuran efektivitas terapi dilakukan dengan menghitung Length of Stay (LOS). Pengolahan data LOS dilakukan secara statistik dengan metode uji t tidak berpasangan (Cahyaningtyas et al., 2013).

Outcome klinis diukur dari LOS maksimal 5 hari ditandai dengan suhu tubuh normal yang tertulis pada rekam medis. Length of Stay (LOS) merupakan parameter keberhasilan pengobatan dan saat tersebut menentukan efektivitas antibiotik (Susono et al., 2014).

Analisis biaya dilakukan berdasarkan perspektif rumah sakit dengan melihat beberapa komponen biaya yang diperlukan pasien selama masa rawat inap yaitu meliputi instalasi rawat darurat, kelas perawatan, pemeriksaan laboratorium, instalasi gizi, biaya antibiotic, dan biaya penunjang.

Analisis biaya yang digunakan untuk menentukan efektivitas biaya 
adalah metode perhitungan ACER dan ICER. ACER dihitung dengan membandingkan rata-rata medical cost dengan efektivitas terapi. Sedangkan ICER dihitung melalui rasio selisih nilai ACER dengan selisih efektivitas terapi.

\section{Hasil dan Pembahasan}

\section{Gambaran Karakteristik Pasien}

Hasil penelitian menunjukkan bahwa jumlah pasien infeksi saluran kemih pada perempuan (61\%) lebih besar daripada pasien laki-laki (39\%). Timbulnya infeksi saluran kemih lebih disebabkan oleh bakteri yang umumnya mengkoloni pada bagian bawah uretra. Selain itu juga karena uretra wanita pendek sehingga infeksi saluran kemih lebih sering terjadi pada wanita (Gutiérrez-Castrellón et al., 2015). Hal ini bersinergi dengan penelitian yang menyatakan bahwa pasien infeksi saluran kemih yang berjenis kelamin perempuan lebih banyak yaitu $81,81 \%$ daripada pasien yang berjenis kelamin laki-laki yaitu sebesar 18,19\% (Nalang et al., 2018).

Berdasarkan hasil penelitian diperoleh data pasien infeksi saluran kemih usia 46 sampai 55 tahun sebesar $37,5 \%$, yang dapat dilihat pada Tabel 1 . Prevalensi ISK meningkat pada usia 46 sampai 55 tahun karena pada usia tersebut terjadi penurunan daya tahan tubuh sehingga dapat terjadi peningkatan kerentanan pada infeksi (Flores-Mireles et al., 2015). Hal yang sama diperoleh pada penelitian yang dilakukan oleh Nalang et al. (2018) yang menunjukkan bahwa pasien pada kelompok usia 56 hingga 65 tahun lebih rentan terjadi atau beresiko mengalami infeksi saluran kemih (Nalang et al., 2018).

Tabel 1. Karakteristik jenis kelamin dan usia

\begin{tabular}{ccc}
\hline Karakteristik & Jumlah Pasien & Persentase (\%) \\
\hline $\begin{array}{c}\text { Jenis Kelamin } \\
\text { Perempuan } \\
\text { Laki-Laki }\end{array}$ & 39 & \\
& 25 & 61 \\
Usia & & 39 \\
$26-35$ & 8 & \\
$36-45$ & 9 & 12,5 \\
$46-55$ & 24 & 14,1 \\
$56-65$ & 14 & 37,5 \\
$>65$ & 9 & 21,8 \\
\end{tabular}

Pengukuran Efektivitas

Dalam penelitian ini pengukuran efektivitas terapi didasarkan pada durasi lama rawat/Length of Stay (LOS) pada masing-masing pasien yang diberikan terapi seftriakson dan pasien yang diberikan terapi siprofloksasin hingga mencapai outcome terapi yang 
diinginkan (Flores-Mireles et al., 2015). Secara klinis didapatkan demam (38,5-40 $\left.{ }^{\circ} \mathrm{C}\right)$. Outcome terapi yang diinginkan ditunjukkan pada lama rawat pasien yang ditandai dengan penurunan suhu tubuh ke suhu normal (Tabel 2). Lama rawat yang efektif berdasarkan clinical pathway rumah sakit adalah kurang dari 5 hari (PFT, 2019). Angka efektivitas diperoleh dari lama hari pasien yang menjalani lama rawat kurang dari sama dengan 5 hari. Data lama rawat pasien tercantum pada Tabel 3 .

Tabel 2. Pengukuran luaran klinis

\begin{tabular}{ccc}
\hline Antibiotik & Waktu Bebas Demam (rujukan) & Rata-Rata \\
\hline Seftriakson & \multirow{2}{*}{$36,5^{\circ} \mathrm{C}$ (3 hari) } & $36 \pm 0,5^{\circ} \mathrm{C}(4$ hari) \\
Siprofloksasin & & $36 \pm 1^{\circ} \mathrm{C}$ (5 hari) \\
\hline
\end{tabular}

Sumber rujukan: Clinical Pathway RS

Tabel 3. Frekuensi lama rawat inap pasien infeksi saluran kemih

\begin{tabular}{ccccc}
\hline Antibiotik & Mean & SD & \% & p value \\
\hline Seftriakson & 4,468 & $\pm 0,999$ & 87,5 & 0,587 \\
Siprofloksasin & 4,688 & $\pm 1,991$ & 78,1 & \\
\hline
\end{tabular}

Sumber: data primer 2017

Berdasarkan data pada Tabel 3, penggunaan seftriakson dalam terapi infeksi saluran kemih memiliki rata-rata lama rawat 4,468 hari lebih singkat dibandingkan penggunaan siprofloksasin dengan rata-rata rawat inap 4,688 hari. Angka probabilitas pasien yang menerima seftriakson sebesar $87,5 \%$ $(0,875)$ sedangkan angka probabilitas pasien yang menerima siprofloksasin sebesar 78,1\% (0,781). Berdasarkan data pada Tabel 3 dapat dilihat $p$-value dari lama rawat terapi antibiotik seftriakson dan siprofloksasin. Lama rawat pada Tabel 3 memiliki nilai $p=0,587$ artinya tidak terdapat beda yang signifikan antara lama rawat seftriakson dan siprofloksasin pada pasien infeksi saluran kemih.
Analisis Biaya

Biaya dalam penelitian ini merupakan biaya medik langsung pada pasien ISK dengan terapi seftriakson maupun siprofloksasin selama rawat inap di Rumah Sakit $X$, Kabupaten Jombang. Biaya medik langsung meliputi biaya instalasi rawat darurat, biaya kelas perawatan, pemeriksaan radiologi, pemeriksaan laboratorium, instalasi gizi, biaya antibiotik, dan biaya penunjang selama perawatan. Perhitungan biaya medik langsung pada pasien ISK yang menjalani rawat inap di Rumah Sakit $X$ Jombang periode Januari-Desember 2017 yang menggunakan terapi seftriakson dan siprofloksasin terdapat pada Tabel 4. 
Tabel 4. Data biaya medik langsung pasien infeksi saluran kemih dengan terapi seftriakson dan siprofloksasin

\begin{tabular}{lrr}
\hline \multirow{2}{*}{ Komponen Biaya } & \multicolumn{2}{c}{ Biaya rata-rata (Rp) } \\
\cline { 2 - 3 } & Kelompok Seftriakson & Kelompok Siprofloksasin \\
\hline Instalasi Rawat Darurat & $166.131,75$ & $143.985,09$ \\
Kelas Perawatan & $369.869,56$ & $406.689,63$ \\
Pemeriksaan Radiologi & $41.562,50$ & $231.725,47$ \\
Pemeriksaan Laboratorium & $230.415,98$ & $8.781,25$ \\
Instalasi Gizi & $3.812,50$ & $3.000,00$ \\
Biaya Antibiotik & $91.116,08$ & $165.737,47$ \\
Biaya Penunjang & $234.564,08$ & $197.523,46$ \\
\hline Total biaya langsung rata- & $\mathbf{9 0 2 . 9 0 8 , 3 7}$ \\
rata (medical cost) & \multicolumn{2}{c}{$\mathbf{~} \mathbf{0 , 2 2 7}$} \\
\hline \multicolumn{2}{c}{$\boldsymbol{p}$ value } & \multicolumn{2}{c}{} \\
\hline
\end{tabular}

Sumber: Data Primer, 2017

Tabel 4 menunjukkan bahwa pasien ISK dengan kelompok terapi antibiotik seftriakson membutuhkan medical cost yang lebih rendah dibandingkan dengan pasien ISK pada kelompok terapi antibiotik siprofloksasin. Uji statistik dilakukan dengan menggunakan metode uji-t tidak berpasangan. Dihasilkan nilai $p$ ( $p$ value) 0,227 yang menunjukkan bahwa tidak ada perbedaan yang bermakna antara total biaya langsung rata-rata kelompok seftriakson dengan kelompok siprofloksasin.

Perhitungan Efektivitas Biaya

Nilai ACER menunjukan bahwa setiap peningkatan 1 unit efektivitas dibutuhkan biaya sebesar ACER (Citraningtyas et al., 2019). Pada penelitian ini, efektivitas biaya dihitung dengan membandingkan medical cost dan efektivitas dari seftriakson dan siprofloksasin (Average Cost Effectiveness Ratio/ACER). Hasil perhitungan terdapat pada Tabel 5.

Tabel 5. Hasil perhitungan ACER

\begin{tabular}{lccccc}
\hline \multicolumn{1}{c}{ Antibiotik } & $\begin{array}{c}\text { Rata-Rata } \\
\text { Biaya Langsung (Rp) }\end{array}$ & $\boldsymbol{p}$ & $\begin{array}{c}\text { Probabilitas } \\
\text { (Efektivitas) }\end{array}$ & $\boldsymbol{p}$ & ACER \\
\hline Seftriakson & $902.908,37$ & 0,227 & 4,468 & 0,587 & $1.031 .895,28$ \\
Siprofloksasin & $959.918,91$ & & 4,688 & & $1.229 .089,51$ \\
\hline
\end{tabular}

Nilai ACER seftriakson menunjukkan nilai yang lebih rendah daripada nilai ACER siprofloksasin. Hal ini bersinergi dengan penelitian yang menyatakan bahwa nilai ACER seftriakson lebih kecil yakni sebesar Rp503.438,33 daripada nilai ACER siprofloksasin yakni sebesar 
Rp529.169,69 pada pasien infeksi saluran kemih di RSUP Prof. Dr. R. D. Kandou Manado (Nalang et al., 2018).

Berdasarkan nilai ACER dan efektivitas dilakukan analisa efektivitasbiaya berdasarkan kurva decision rules of cost-effectiveness analysis. Berdasarkan kurva tersebut, suatu intervensi kesehatan memiliki efektivitas lebih tinggi dengan biaya yang lebih rendah dibanding intervensi standar, intervensi alternatif ini masuk ke kuadran adopt dan menjadi pilihan utama (Kemenkes,
2013). Pada penelitian ini menunjukkan bahwa seftriakson memiliki efektivitas lebih tinggi dengan biaya yang lebih rendah dibandingkan dengan siprofloksasin. Sehingga, seftriakson dapat digunakan sebagai pilihan utama dalam terapi pasien infeksi saluran kemih. Pada perhitungan nilai ICER pada penelitian ini didapatkan nilai sebesar Rp259.138,82. artinya ada biaya tambahan sebesar Rp259.138.82 per outcome terapi.

Tabel 5. Perhitungan ICER

\begin{tabular}{lccc}
\hline Antibiotik & $\begin{array}{c}\text { Rata-Rata } \\
\text { Biaya Langsung (Rp) }\end{array}$ & $\begin{array}{c}\text { Efektivitas Terapi } \\
\text { (hari) }\end{array}$ & ICER (Rp) \\
\hline Seftriakson & $902.908,37$ & 4,468 & $259.138,82$ \\
Siprofloksasin & $959.918,91$ & 4,688 & \\
\hline
\end{tabular}

\section{Simpulan}

Hasil penelitian menunjukkan bahwa seftriakson dapat digunakan sebagai pilihan utama dalam terapi pasien infeksi saluran kemih. Namun tidak ditemukan perbedaan yang bermakna pada efektivitas dan biaya antara seftriakson dan siprofloksasin. Pada perhitungan nilai ICER pada penelitian ini didapatkan nilai sebesar Rp259.138,82. Artinya ada biaya tambahan sebesar Rp259.138.82 per outcome terapi.

\section{Daftar Pustaka}

Abbo, L.M. dan Hooton, T.M. 2014. Antimicrobial stewardship and urinary tract infections.
Antibiotics, 3(2):174-192.

Admaja, W., Herowati, R., Andayani, T.M. 2019. Analisis efektivitas biaya terapi penggunaan antibiotik profilaksis cefazoline dan amoxicillin pada kasus bedah sesar di RSUD Jombang tahun 2017. Jurnal Wiyata: Penelitian Sains dan Kesehatan, 6(1):40-53.

Cahyaningtyas, Rahmatini, Sedjahtera, K. 2013. Hubungan lama terapi antipsikotik dengan kadar SGOT dan SGPT pada pasien skizofrenia di RSJ Prof. H.B. Sa'anin. Jurnal Kesehatan Andalas, 6(1):128-133.

Citraningtyas, G., Ruru, R.I., Nalang, A. 
2019. Analisis efektifitas biaya penggunaan antibiotik sefiksim dan sefotaksim pasien diare di Rumah Sakit X tahun 2017. Jurnal Manajemen dan Pelayanan Farmasi, 8(4):145152.

Flores-Mireles, A.L., Walker, J.N., Caparon, M., Hultgren, S.J. 2015. Urinary tract infections: epidemiology, mechanisms of infection and treatment options. Nature Reviews Microbiology, 13(5):269-284.

Firdiana, S.E. dan Farida, H. 2016 Perbandingan efektivitas seftriakson dengan siprofloksasin pada kuman Neisseria gonorrhoeae secara in vitro. Jurnal Kedokteran Diponegoro, 5(4):1736-1742.

Gutiérrez-Castrellón, P., Díaz-García, L., de Colsa-Ranero, A., CuevasAlpuche, J., Jiménez-Escobar, I. 2015. Efficacy and safety of ciprofloxacin in the treatment of urinary tract infections (UTI) in adults: a systematic review with meta-analysis. Gaceta Medica de Mexico, 151(2):225-244.

$\begin{array}{cr}\text { Kementerian Kesehatan } & \text { Republik } \\ \text { Indonesia. 2013. } & \text { Pedoman } \\ \text { Penerapan } & \text { Kajian } \\ \text { Farmakoekonomi. } & \text { Jakarta: } \\ \text { Kemenkes RI. } & \end{array}$

Perrault, L., Dahan, S., Iliza, A.C., LeLorier, J., Zhanel, G.G. 2017. Cost-effectiveness analysis of fosfomycin for treatment of uncomplicated urinary tract infections in Ontario. Canadian Journal of Infectious Diseases and Medical Microbiology, 2017: Article ID 6362804

PFT. 2019. Clinical Pathway RSUD Jombang.

Nalang, A., Citraningtyas, G., Lolo, W.A. 2018. Analisis efektivitas biaya (cost effectiveness analysis) pengobatan pneumonia menggunakan antibiotik seftriakson dan sefotaksim di RSUP Prof. Dr. R.D. Kandou Manado. Pharmacon, 7(3):321329.

Pranoto, E., Kusumawati, A., Hapsari, I. 2012. Infeksi saluran kemih di instalasi rawat inap RSUD Banyumas periode Agustus 2009-Juli 2010. Pharmacy, 09(02):9-18.

Susono, R.F., Sudarso, Galistiani, G.F. 2014. Cost effectiveness analysis pengobatan pasien demam tifoid pediatrik menggunakan cefotaxime dan chloramphenicol di Instalasi Rawat Inap RSUD Prof. Dr. Margono Soekarjo. Pharmacy, 11(01):86-97. 